\title{
Initial research on recycled tyre bales for road infrastructure applications
}

\author{
Aleksander Duda, Dariusz Sobala \\ Rzeszow University of Technology \\ Faculty of Civil and Environmental Engineering and Architecture \\ e-mail: aduda@prz.edu.pl,dsobala@prz.edu.pl
}

\begin{abstract}
The paper reviews selected surveys carried out within the R\&D project, co-financed with the European Regional Development Fund, called "ReUse - Innovative Recycling Materials, Enhancing the Sustainability of Bridge Facilities" (Innotech No. K3 / IN3 / 38/228116 / NCBiR / 15). The aim of the project and conducted research is to develop and implement innovative, cheap and environmentally-friendly recycled construction material in the form of tyre bales made from compressed used car tyres. This material is likely to be applied in civil engineering, especially in transport infrastructure, geotechnical and hydraulic engineering. New material is cheap and has unique properties such as low weight, high water permeability, high vibration and noise-damping capacity, low pressure coefficient values and other parameters that technically and economically allow it to replace natural aggregates. The extensive practical application of new material will facilitate the replacement of waste management methods with the environmentally friendly ones.
\end{abstract}

Key words: aggregate, earth structures, tyre recycling, tyre bales, $R \& D$ project

\section{Introduction}

\section{$1.1 \quad$ Tyre bales}

Tyre bales from compressed used car tyres (CUCT) are a new recycled building material which is a product of tyre recycling process. Tyre compressing and packaging is a solution resulting from the necessity to limit the sizes of landfill sites and to reduce the risk of spontaneous combustion of tyres there. When applied in construction engineering, compressing and packaging positively affect cost-effectiveness and transport options as well as mechanical properties of the material. Compressed tyres are bound with plastic bands or galvanised steel wires of high strength. A tyre bale looks like a rectangular (Fig. 1) whose height corresponds the maximum height of compressed tyres, width results from the size of the press and length depends on the number of compressed tyres (most often 100-140). The process of tyre pressing and packaging applied in Great Britain has been presented in details in the specification [1]. 
The advantages which are mainly the low production and transportation costs make tyre bales technically and economically efficient construction material. Yet, the introduction of a new material requires extensive research aimed at determining its physical, mechanical and environmental properties.

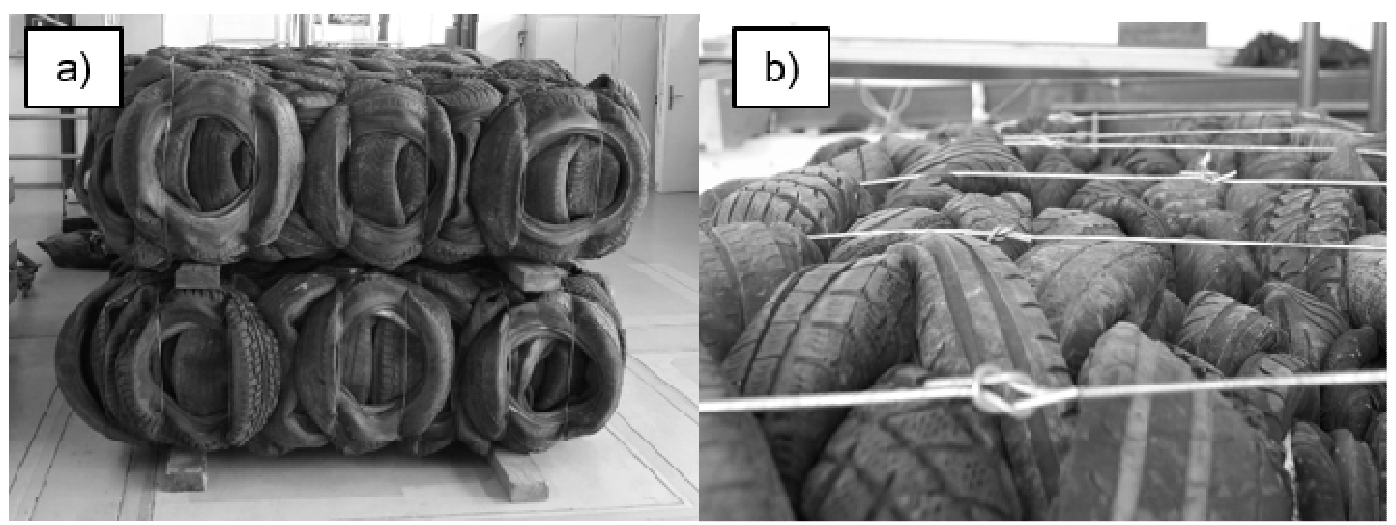

Figure 1: Tyre bales (a) and connection of binding wires (b)

Table 1 presents basic properties of tyre bales and natural aggregates. In most cases the properties of tyre bales are more advantageous. One of the crucial drawbacks of the bales is their high compressibility which results from the small values of deformation modulus. In practical applications this drawback can be equalised by means of suitable design and construction solutions, e.g. in embankments, transmission layers of suitable depth of primary aggregates are applied above tyre bales. Such a transmission layer reduces the deformations of the road surface to the acceptable level.

Table 1: Properties of tyre bales in comparison with natural aggregates

\begin{tabular}{|l|c|c|c|}
\hline Property & Tyre bales & $\begin{array}{c}\text { Minerals } \\
(\text { sand, gravel })\end{array}$ & Source \\
\hline Unit weight $\left[\mathrm{kN} \cdot \mathrm{m}^{-3}\right]$ & $5 \div 6$ & $18 \div 20$ & {$[1]$} \\
\hline Friction angle $\left[{ }^{\circ}\right]^{*}$ & $35 \div 36$ & {$[-]$} & {$[2]$} \\
\hline Friction angle $\left[{ }^{\circ}\right]$ & {$[-]$} & $35 \div 40$ & {$[-]$} \\
\hline Elastic modulus $[\mathrm{MPa}]$ & $0,8 \div 1,3$ & $40 \div 100$ & {$[1]$} \\
\hline Permeability coefficient $\left[\mathrm{cm} \cdot \mathrm{s}^{-1}\right]$ & $2 \div 4$ & $0,1 \div 1$ & {$[1]$} \\
\hline Thermal conductivity $\left[\mathrm{W} \cdot(\mathrm{m} \cdot \mathrm{K})^{-1}\right]$ & 0,07 & $0,4 \div 0,7$ & {$[2]$} \\
\hline Vibro insulation & very high & low & {$[2]$} \\
\hline * value refers to the friction between tire bales without backfill \\
\hline
\end{tabular}

\subsection{Applications of tyre bales in civil engineering}

The CUCT tyre bales were first applied in 1997 in the USA. Since then, over 30 projects have been implemented, mainly in the USA and Great Britain. In Poland, tyre bales have been used only in research projects - test stands of natural size. Below, the opportunities to use CUCT 
tyre bales in civil engineering are discussed, illustrated with the structures constructed worldwide.

Remediation of a failed slope, the USA [3]:

In 2001, tyre bales were used to repair soil cut slope at Interstate Highway 30 in Texas. The slope is 6.1 metres high and 46 metres long. It was repaired using CUCT tyre bales (Fig. 2) placed on the layers of clay, clay loam and silty clay, prone to rising moisture.
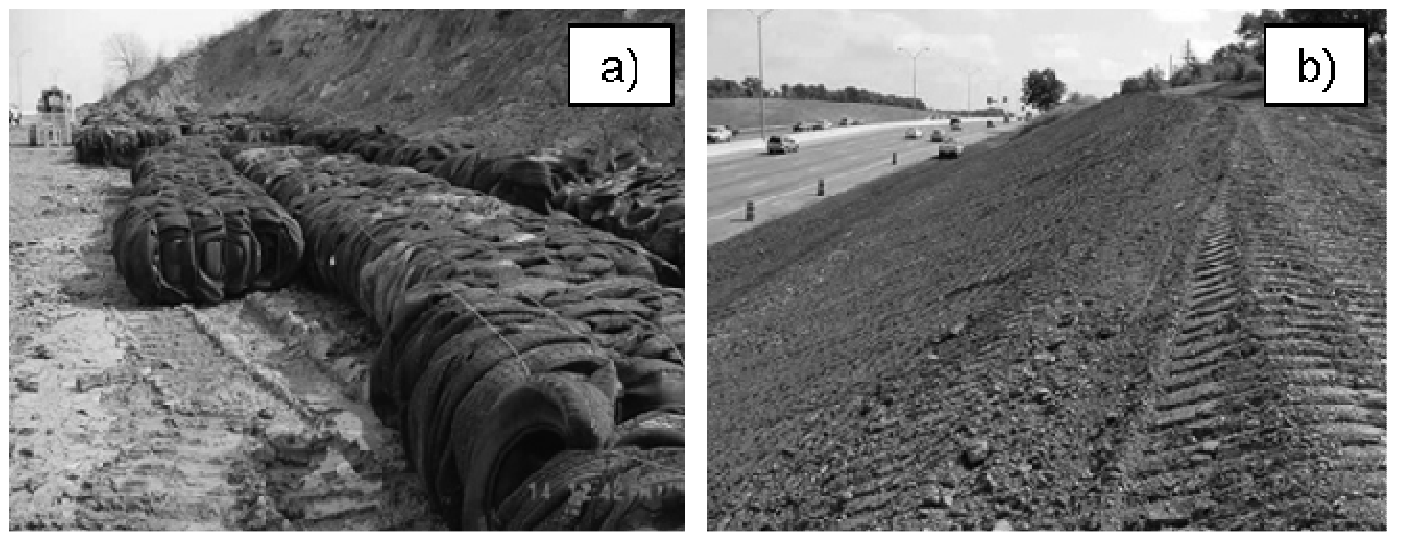

Figure 2: Slope failure repair: a) incorporation of tyre bales b) backfilling and profiling of the slope [4]

A421 motorway section in Marston Moretaine, Great Britain [5]:

In the discussed section of A421 motorway there were the layers of deformable medium plastic soil with the bearing capacity of $25-35 \mathrm{kPa}$ and thickness of $20 \mathrm{~m}$. After an economic analysis of various possible options, CUCT tyre bales were chosen as lightweight fill for the embankment. The spaces between the bales were filled with light expanded clay aggregate LECA. Above the bales one-metre-deep transmission layer was constructed, and for 6 months the embankment was overloaded in order to accelerate the consolidation of deformable subgrade. This was the first application of tyre bales to construct a national road.
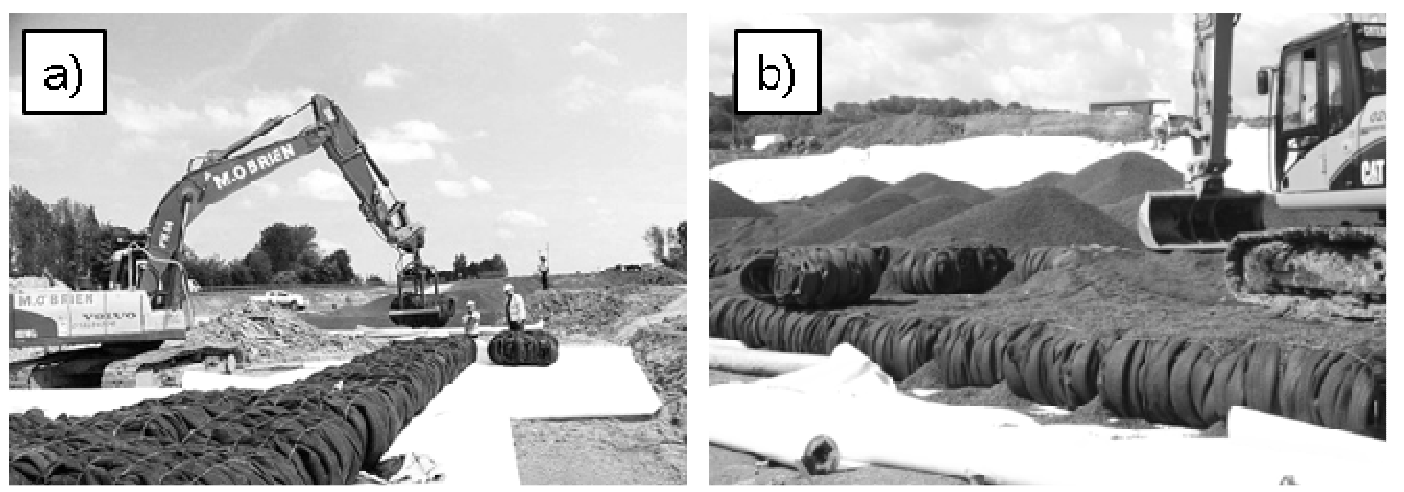

Figure 3: Construction of embankment: a) incorporation of the tyre bales b) filling tyre bales with Light Expanded Clay Aggregate (LECA) [6] 


\section{Laboratory tests on tyre bales}

\subsection{Scope of research}

Roads and Bridges Department at Rzeszów University of Technology is running laboratory tests on mechanical properties of a new recycled material in the form of CUCT tyre bales. The tests concern:

[1] shear strength of geocomposites which consist of CUCT tyre bales and filling materials such as rubber aggregate, expanded clay aggregate and natural aggregate

[2] determination of the stiffness of CUCT tyre bales

[3] creep of CUCT tyre bales

[4] wires binding CUCT tyre bales and wire connections.

\subsection{Shear strength}

The tests on shear strength of geocomposites (CUCT tyre bales with the layer of filling material) have been completed. They aimed at determining shear resistance in the interface layer at the point of contact of tyre bales and filling material. The geocomposite which underwent tests was made of CUCT tyre bales and backfill of medium-sized sand, geotechnical expanded clay aggregate or rubber aggregate. Three test specimens of geocomposite were prepared for each type of backfill. Due to the lack of standard research procedures, to determine the mechanical parametres of the geocomposite made from tyre bales it was necessary to elaborate new research procedures and individual research programmes. The general idea of shear strength tests was adopted according to [7]. In order to conduct tests it was necessary to design individual large-size test stands and construct them in the hall of Structure Testing Laboratory at Rzeszów University of Technology (Fig. 4).
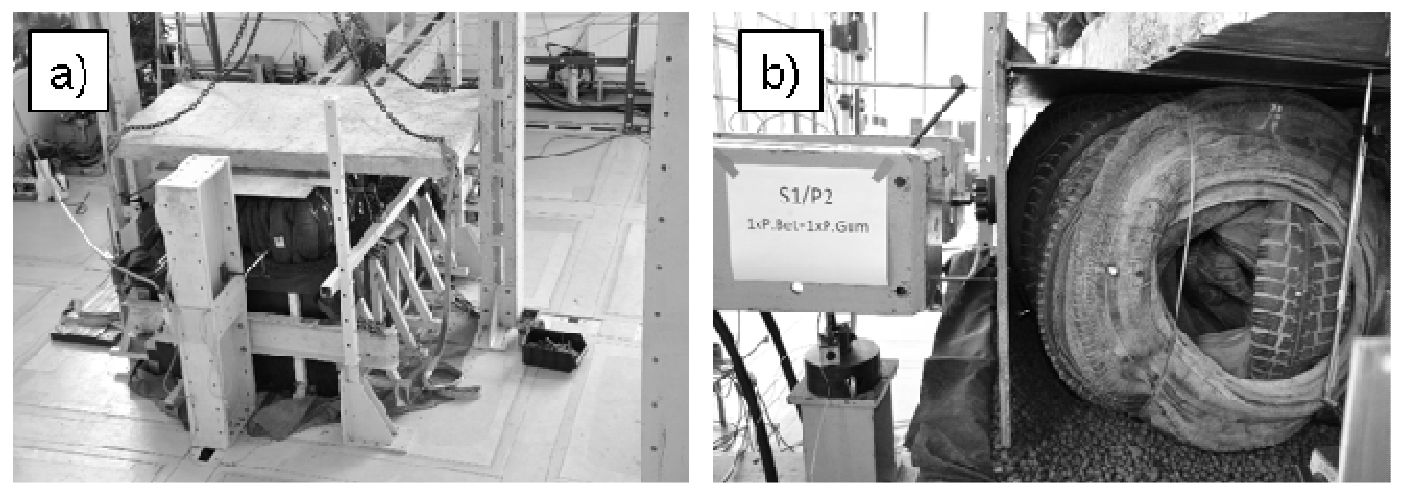

Figure 4: Shear resistance test: view of the test stand (a), location of horizontal shear application(b)

The conducted tests showed high shear resistance which proves very good cooperation of backfill and CUCT tyre bales, better than cooperation of steel and concrete. The tests results allowed to choose the optimal filling material for the geocomposite used in field tests. Figures $5 \mathrm{a}$ and $5 \mathrm{~b}$ show the sample diagram of shearing of geocomposite specimen with the backfill of geotechnical expanded clay aggregate which allowed to determine the mechanical parametres of the interface layer. The diagram (Fig. 5c and 5d) shows the test result and its analysis for three specimens of geocomposite with the backfill of medium-sized sand. 

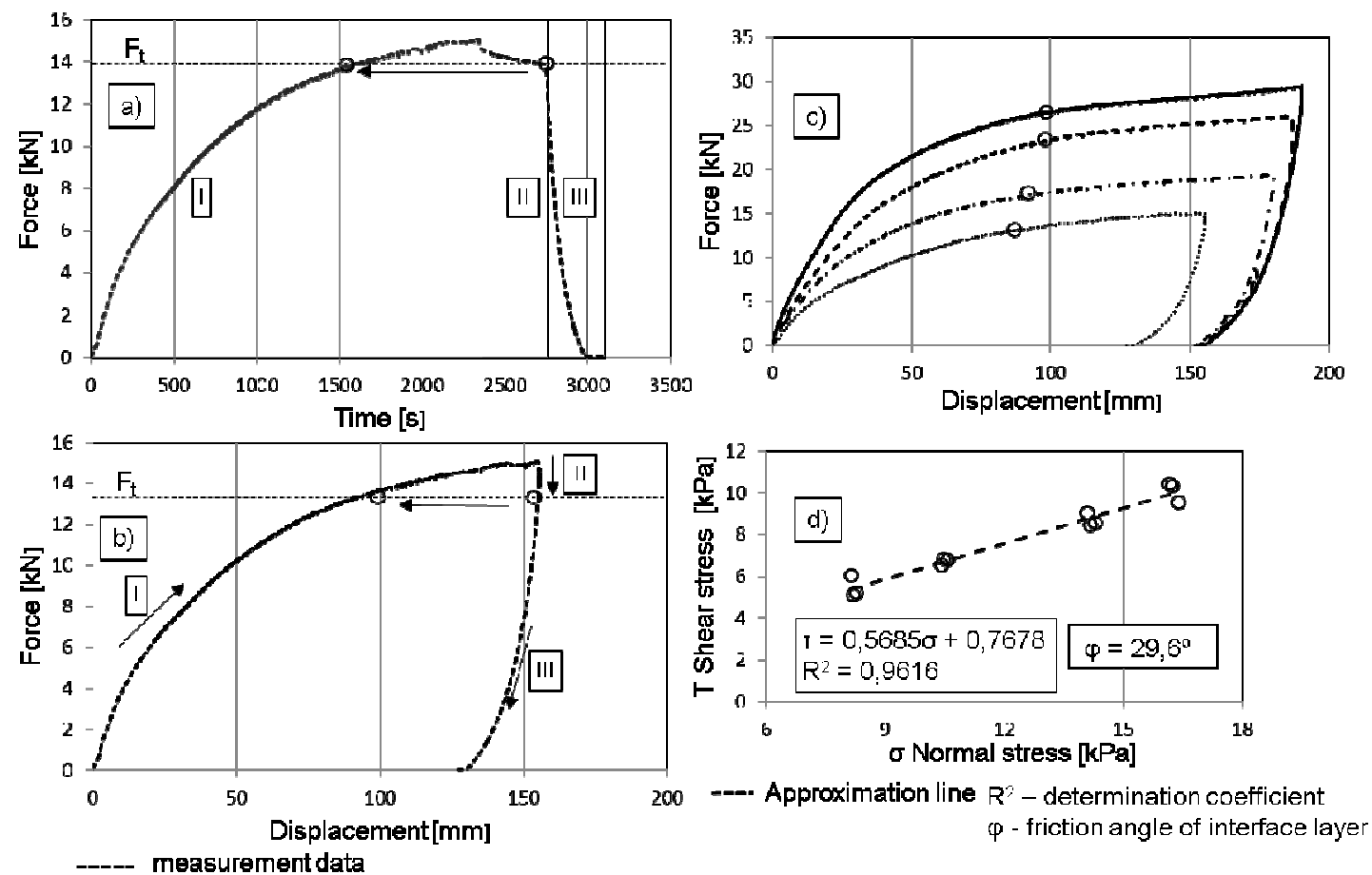

- level adoption of sustainable shear force $F_{t} \quad L$

I - loading, II - sustained displacement, III - unloading

Figure 5: Shear strength test: (a) force-time relation (b) force-displacement relation for single specimen, c) summary of shear strength test on specimen P2 for backfill of medium-sized sand, d) mechanical parameters of the interface layer for backfill of medium-sized sand

\subsection{Determination of CUCT tyre bales stiffness}

The successive tests aimed at the determination of stiffness modulus of ready tyre bales. The tests were carried out with six specimens - CUCT tyre bales - placed on the rigid foundation and evenly loaded with a hydraulic jack by means of a rigid top plate (Fig. 6a). The tests were conducetd under permanent controlled increase in pressure force applied by $0.5 \mathrm{kN} / \mathrm{s}$ up to do assumed value of approx. $260 \mathrm{kN}$, which corresponds the pressure force of approx. $100 \mathrm{kPa}$ (linear increase in displacements), and up to the value of breaking strength of approx. $350 \div 450 \mathrm{kN}$ - the test stand was damaged as a result of displacement and shear of jack's joint. (Fig. 6b). 

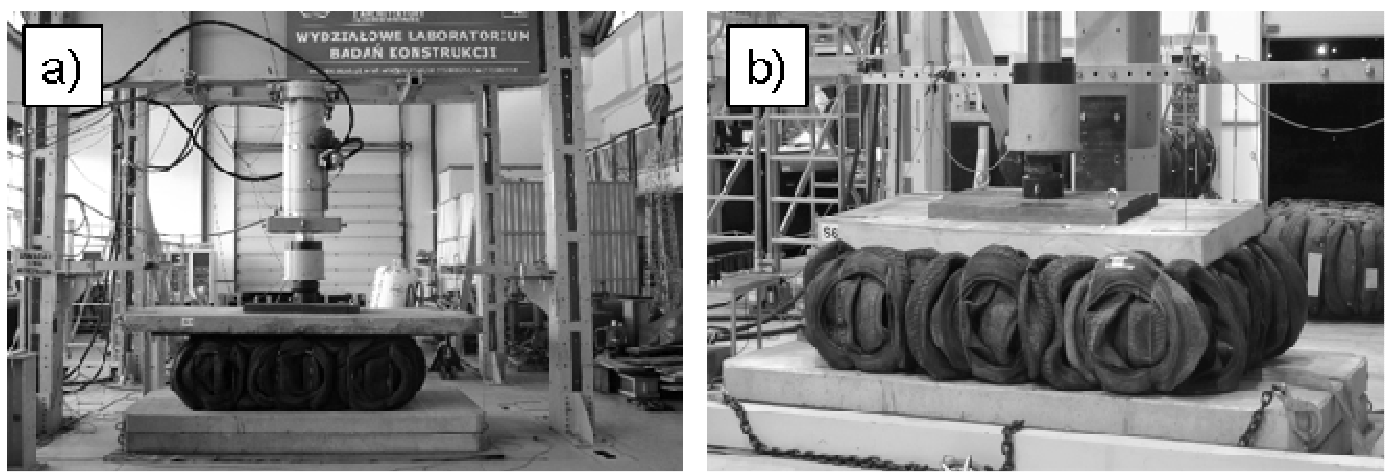

Figure 6: Stiffness tests on tyre bales: a) test stand for compressive strength b) test stand failure due to the uneven deformation of the tyre bale, resulting in the inclination of the top plate at the end of tests

Figure 7 shows the relation between compression strength and mean values of deformation modulus in subsequent stages of load tests. The tests on CUCT tyre bales stiffness allowed to determine the value of initial deformation modulus in the range of between 700 and $934 \mathrm{kPa}$, and the value of secondary deformation modulus for CUCT tyre bales in the range of between 1180 and $1377 \mathrm{kPa}$. The values of initial stiffness moduli, determined as a result of conducted tests, comply with the ranges quoted in the literature, i.e. $800 \div 1100 \mathrm{kPa}$ [2]. The tests results positively validated the assumed pressure force in the range of $100-130 \mathrm{kPa}$; exceeding this value results in non-linear increase in deformation of CUCT tyre bales.

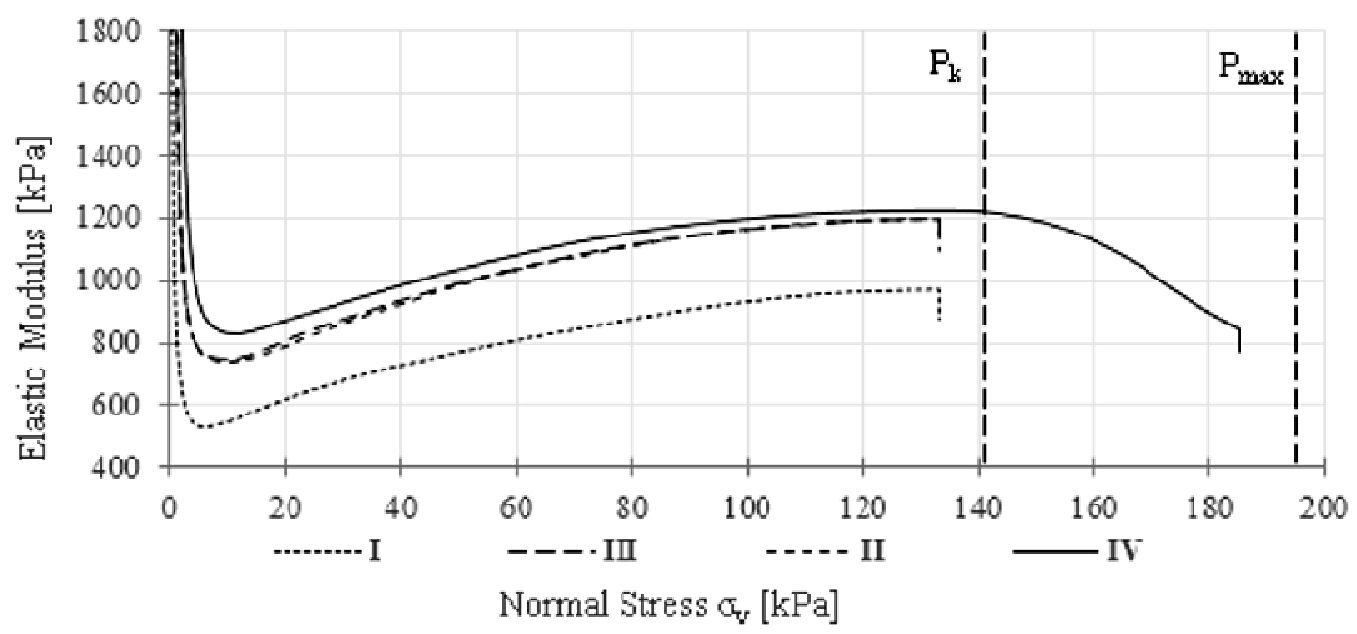

I - IV load stages (in each: loading, sustained force and unloading)

$P_{k}$ - level adoption of start plastic stress

$P_{\max }$ - Maximum stress

Figure 7: Mean deformation modulus for specimen S5 in subsequent load cycles.

\section{Conclusion}

The laboratory tests on tyre bales conducted so far have confirmed the assumptions made to develop current field tests on a large-sized test stand, located in Dębica, Poland (Fig. 8). The 
test stand includes a deep test chamber with a mobile wall simulation, as the need arises, a retaining wall or a relocating wall of a bridge abutment and three sections of an access road where: (1) CUCT tyre bales have not been applied, (2) CUCT tyre bales have been applied in one layer, (3) CUCT tyre bales have been applied in two layers.
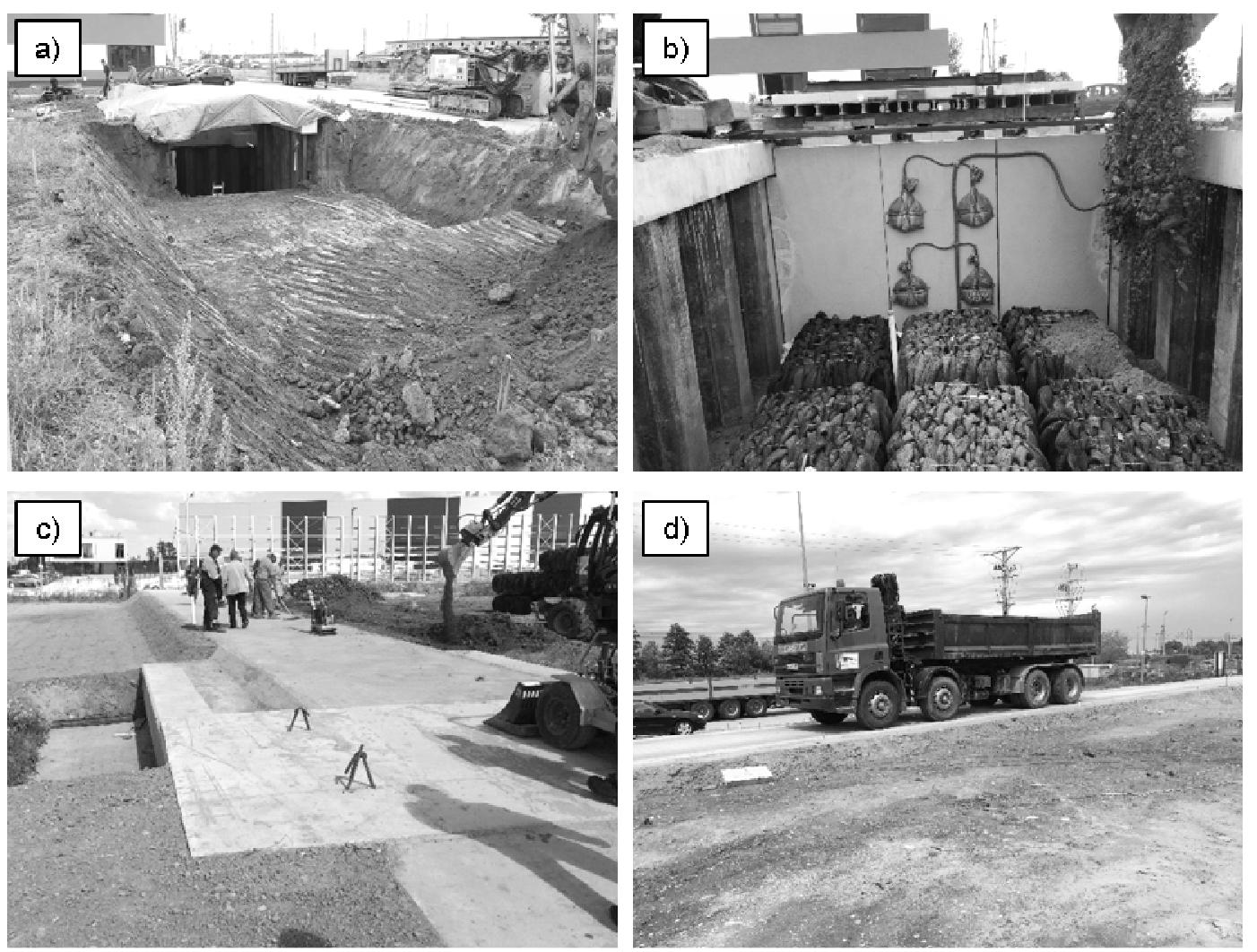

Figure 8: Test stand for field tests: a) test chamber and excavation for approach road under construction, b) filling test chamber with tyre bales and backfill c) finishing works after construction, d) static and dynamic test load of test chamber and approach road section

The aims of current field tests conducted at a large-sized stand are:

- to attempt, under realistic conditions, to implement tyre bales in the road embankment and in the close vicinity of the retaining wall/the abutment of an integrated bridge

- to determine the value and the distribution of pressure on the retaining structure of the geocomposite made up of CUCT tyre bales and backfill, under the conditions of backfill load, static load and functional surcharge

- deformations of the access area to the integrated bridge abutment, whose backfill has been made from CUCT tyre bales and filling material and

- the tests on vibration damping by the embankments filled with CUCT tyre bales.

The results of the field tests, when they have been completed, will be the subject of separate publications.

The tests have been performed under the project co-financed with the European Regional Development Fund called "ReUse - Innovative Recycling Materials, Enhancing the Sustainability of Bridge Facilities" (Innotech No. K3 / IN3 / 38/228116 / NCBiR / 15), 
implemented by the consortium of Remost Debica sp. z o. o., Promost Consulting sp. $k$. (Leader of consortium), Geotech Rzeszow sp. z o. o. and Rzeszow University of Technology.

\section{References}

[1] PAS 108:2007 - Specification for the production of tire bales for use in construction. British Standards Institution

[2] Zornberg, J. G., Christopher, B. R., and Oosterbaan, M. D. (2005), Tire Bales in Highway Applications: Feasibility and Properties Evaluation. Colorado Department of Transportation, Report No. CDOT-DTD-R-2005-2, Denver, Colorado.

[3] Prikryl, W., Williammee, R. and Winter, M. G. (2005), "Slope Failure Repair Using Tyre Bales at Interstate Highway 30, Tarrant County, Texas, USA," Quarterly Journal of Engineering Geology and Hydrogeology, Vol. 38, pp. 377-386.

[4] http://qjegh.geoscienceworld.org/content/38/4/377

[5] Hodgson, I. F., Beales, S. P. and Curd, M. J. (2012), "Use of tyre bales as lightweight fill for the A421 improvements scheme near Bedford, UK". Engineering Geology Special Publications, 26, 101-108, https://doi.org/10.1144/EGSP26.12

[6] https://www.newcivilengineer.com/recycled-tyre-bales-tread-carefully/5208902.article

[7] PKN-CEN ISO/TS 17892-7:2009. Grunty budowlane - badanie na ściskanie gruntów drobnoziarnistych w jednoosiowym stanie naprężenia. 